\title{
Why Jainism and Bioethics?
}

Jainism is a religious tradition and philosophical system rooted in India whose texts and practices are perhaps more strongly focused on the ethics of life and death than any other tradition in the world. Although it does not offer a thoroughgoing "bioethics" in the modern sense, Jainism does present a detailed account of birth, life, and death; a meticulous taxonomy of diverse life-forms; a path of ethical conduct characterized by nonviolence toward all living beings; and a complex development of approaches to medical treatment from antiquity up to the present. Some of the bioethical issues faced by contemporary Jains are similar to the ethical challenges faced by Jains throughout history, while others are without precedent and have required creative ethical responses, either because they have arisen as a result of modern scientific and technological advances or because they are emerging in new social and cultural contexts.

Considering the rich history of Jain encounters with the dilemmas of birth, life, and death, the absence of a book on Jainism in relation to contemporary bioethical issues presents a significant gap in both the fields of bioethics and Jain studies. This book addresses that gap in two distinct ways, mirrored in its two-part structure. In part 1, we explore foundational Jain principles for bioethics based on rigorous analysis of primary sources and available secondary literature. In part 2, we identify provisional principles of application for modern bioethical dilemmas by examining approaches to specific ethical issues relating to birth, life, and death in primary sources and by analyzing scarce contemporary sources on Jainism and bioethics from modern lay Jains, mendicants, and Jain studies scholars, as well as data drawn from an international survey we conducted with Jain medical professionals in 2017-18. We hope that this dual approach of excavating foundational principles and deducing principles of application will make a meaningful contribution to future scholarship and clinical analysis in Jainism and bioethics. 


\section{JAINISM AND JAINS}

In this book, we refer both to "Jainism" and to "Jains." While these two terms understandably overlap, they each have their own historical derivation and they have meaningful differences in contemporary scholarship (Flügel 2005). In our attempt as Jain studies scholars to provide an etic, or outsider, perspective of Jainism in relation to bioethical issues, we have to account for multiple emic, or insider, perspectives that reflect the internal diversity of texts, sectarian disagreements, practices, and individual practitioners. The lens of bioethics unearths complexities too often obscured in a pursuit of "Jainism" or "Jains" as homogeneous realities.

The term "Jain" means one who follows a Jina ("Conqueror" or "Victor"). ${ }^{1}$ Jinas are teachers who, by their own efforts, master the disciplinary practices needed to attain liberation from the cycle of rebirths, known as samsära. They are also called Tìrthankaras or Fordmakers because they create the ford, or tìrtha, for others to follow across the river of samsāra.

Historical records show that Jainism has been present uninterruptedly on the Indian subcontinent for over twenty-five hundred years. Jains themselves, however, understand their tradition to be beginningless and eternal, recognizing twenty-four Jinas who, in our part of the world, appear in certain epochs of time and promulgate the same fundamental doctrine (see chapter 2). Scholars consider the last two of these teachers to be historical persons as evidenced by textual records. The twenty-fourth and last teacher of our current era, Mahāvirra ("Great Hero"), lived in the fifth century BCE, and the twenty-third teacher, Pārśvanātha, lived approximately 250 years before him. ${ }^{2}$ Prior to their liberation, both Jinas oversaw a fourfold community of mendicant monks and nuns, as well as laymen and laywomen householders.

Mahāvīra was an elder contemporary of the Buddha, and while we do not know if they ever actually met, a Buddhist canonical text, Sāmañ̃naphala-sutta, lists Mahāvira as one of the śramana leaders. This indicates that at least the Buddha knew of Mahāvīra (Jacobi 1879, 1-6; Jaini 2001b, 57-60). Śramana ("striver") was a term used for the Buddha, Mahāvira, and other wandering non-Vedic renunciates in the Ganges plain to differentiate them from Vedic priests and renouncers (brähmana) (Dundas 2002, 16). Sramanas rejected the authority of the Vedas and other sacred texts of the brähmanas, their gods, as well as the efficacy of Vedic rituals (Jaini 2001b; Jaini 2001/1979, 2, fn. 2).

The ethical orientation of Jainism seems to emerge hand in hand with its intricate account of living beings. As we detail in chapter 2, the Jain universe is populated by an infinite number of living beings existing in cycles of birth, death, and rebirth who are categorized in myriad ways. These sophisticated classifications indicate an effort to understand what life is and, consequently, what can be violated. Every living being possesses its own core life principle, or jīva, that either accumulates or sheds material karma based on activities of the body, speech, and 
mind. Although the Jain worldview differs considerably from modern biological taxonomies, it nevertheless presents a systematic description of living beings and provides a causal explanation through karma to explain each being's essential qualities, as well as factors of its specific embodiment.

Amid this vibrant universe teeming with a multiplicity of living beings, Mahāvīra centered his teachings on various vows of restraint that we address in chapter 3. The first and foremost of these vows is the restraint of nonviolence, often known by the Sanskrit term ahimsā. Monks and nuns take these vows fully as "great vows" during an initiation that signifies their rebirth into the houseless existence of a mendicant, while lay Jain householders fulfill them partially as "minor vows" in the context of work, family, and social life. From antiquity to the present, the fourfold community of monks, nuns, laymen, and laywomen have developed a distinct-but-symbiotic relationship (which we describe in chapter 3 particularly and which threads through the book as a whole).

In the early centuries of the Common Era, the Jain community divided into two dominant sects, due to a few key differences, one of which is the proper clothing for a mendicant, from which the sect names derive. The larger Śvetāmbara sect refers to "white-clad" mendicants, and the smaller Digambara, or "sky-clad," sect believes that male mendicants seeking liberation must practice nudity. In contrast to Śvetāmbaras, Digambaras maintain that women cannot become liberated. In addition to these two dominant sects, other subsects also split off throughout history, resulting in a diverse Jain community marked by particular differences in belief or ritual practice (Dundas 2002, 45-51; Jain 2012). ${ }^{3}$ In spite of these differences, Jains have remained strongly united on the ethical primacy of nonviolence.

Today, Jainism is a relatively small global community. The World Religions Database (WRD) at Boston University ${ }^{4}$ estimates that Jains make up 0.42 percent (5.85 million) of the Indian population, with approximately 285,000 Jains living in diaspora abroad (Johnson and Grim 2020). ${ }^{5}$ These numbers almost exclusively reflect laity, rather than mendicants, since the latter would be unlikely to participate in government data collection, and fully ordained mendicants cannot travel by mechanized transport to other countries. Researchers estimate the overall Jain mendicant population in modern India as of 1999-inclusive of all sects-to be approximately three thousand monks and nine thousand nuns (Flügel 2006, 362).

The largest populations of Jains outside of India are in Kenya, the United States, the United Kingdom, and Canada, respectively, and there are smaller communities in other countries (Johnson and Grim 2020). In the United States, the WRD estimates the 2020 population of Jains as ninety-seven thousand, ${ }^{6}$ the largest communities being in Northern and Southern California; Chicago, Illinois; Houston, Texas; and the New York-New Jersey region.

In 2014, Jainism was legally designated a distinct "minority religion" by the government of India. ${ }^{7}$ Yet, even as a minority community, Jains have significant influence in the country. According to the National Family Health Survey taken in 
2015-16, Jains have the highest rates of literacy nationally among both men (97.1\%) and women (97.5\%) (Ministry of Health and Family Welfare 2016, 63-65), as well as the highest levels of education. ${ }^{8}$ Jains are the wealthiest community overall, with nearly three-quarters of the population in the top wealth division (31), resulting in a disproportionately high contribution to government tax revenue and the national charity fund. ${ }^{9}$ Jainism has contributed widely to the social, religious, and intellectual history of India, responding to current philosophical debates, producing a vast body of literature, shaping historical trends in arts and architecture (Hegewald 2019), and adapting creative modes of monarchical rule and political participation (Dundas 2007a; Jain 2017).

Unique to this project is the examination of Jain approaches to medicine up to the present day. We provide an overview of Jain attitudes toward medicine in chapter 4, detailing accommodations for ill mendicants even in the earliest strata of the Śvetāmbara canon, followed by an increasing liberalization, including the eventual obligation for mendicants to offer aid to their sick fellow monks and nuns, and the designation of medicine as an acceptable occupation for laity to undertake. Today, Jains have high representation in medical and allied fields, especially in diaspora countries such as the United States. The prevalence of contemporary Jains in medicine, which we describe in chapter 5, provides another motivating factor for our analysis of Jainism and bioethics.

As we explore Jainism in relation to bioethics within part 1, we strive to retain the complexity of evolving concerns, changing terminologies, and textual disagreements over time-between sects and between lay and mendicant viewsin order to preserve a richer account of Jainism as a multifaceted philosophical, religious, and historical tradition. In part 2, we also endeavor to represent a diverse community of "Jains" that includes mendicants and laypeople, Jains in India, Jains who migrated abroad, Jains born outside India, and Jains who retain unique regional and linguistic ties to the subcontinent that inform their identity as culturally Jain and/or as practicing Jains. The results of our research reflect these diverse personal, religious, cultural, and professional contexts, providing multiple angles from which to approach Jain interpretations of bioethical issues.

\section{RELIGION AND BIOETHICS}

In bringing the philosophical-religious tradition of Jainism into dialogue with bioethics, it is helpful to consider the various ways in which religion and bioethics have intersected before. By many accounts, bioethics is a modern, Western, secular humanistic discipline that emerged largely in the United States in the late 1960s and early '7os as a means of addressing moral issues in contemporary medicine. Many of these dilemmas arose from advances in science and technology anachronistic to traditional Jain philosophy, religious ideals, and practices. Life-sustaining technologies, for instance, such as the positive pressure ventilator, produced 
twentieth-century dilemmas surrounding the definition of death and generated questions of resource allocation for bodies that could now survive previously fatal trauma. Additionally, the awareness of egregious healthcare harms required an urgent redress of informed consent principles. The cases that led to this include the Nazi medical experiments of World War II and the forty-year Tuskegee syphilis experiment on African American sharecroppers, wherein researchers failed to provide penicillin to participants after it became a known curative in the 1940s, continuing the study until 1972. Moreover, the burgeoning global pharmaceutical industry necessitated robust international regulations for review and oversight of clinical trials, subject recruitment, and patient protections.

Yet, even in addressing such distinctly modern problems, bioethics as a discipline has been pivotally shaped by enduring philosophical and religious insights that exceed the spheres of science and technology alone. Often overlooked in modern accounts of bioethics is the earliest known reference to "bioethics." Between 1926 and 1927, a German Protestant pastor and ethicist, Fritz Jahr (1895-1953), proposed "Bio-Ethik" as an ethical principle and an interdisciplinary academic discipline needed to explore relationships between the human community and nonhuman living beings (Jahr 1926; Jahr 1927). ${ }^{10}$ Jahr looked to sources that articulated responsive relationships between humans, animals, and plants, including many religious narratives and philosophical figures, as well as Darwin's account of evolution, and the physical and psychological similarities between various forms of life assumed by animal research and revealed in plant studies (Goldim 2009, 378; Sass 2014, 221-22).

Based on these, Jahr proposed the "Bioethical Imperative": "Respect every living being in general as an end in itself and treat it, if possible, as such!" $(2013,21){ }^{11}$ Jahr issued this imperative, which included all living beings, as a critical response to Immanuel Kant's influential concept of the Categorical Imperative that articulated three unconditional moral obligations solely among "rational persons": (a) to act in such a way that the action could become universal law; (b) to treat others as their own end, and not merely as a means; and (c) to respect the selfdetermination of oneself and others. To reconfigure Kant's commitments beyond "rational persons," Jahr envisioned a moral partnership between humans, animals, and plants that pursued appropriate, though not necessarily equal, consideration of the flourishing of all living beings. Despite some fundamental differences, Jahr's broad understanding of life and expansive moral obligations stemming from it bear significant resemblances with Jain ethics.

It is important to note that Jahr was at least somewhat familiar with religions of India and their ethics, and it is perhaps no coincidence that in his 1927 introduction of the term bioethics, he specifically references a religious tradition that seems to be Jainism. He calls it "Yoga":

The yoga repentant [Jogabüßer] under no circumstances is allowed to live at the cost of co-creatures; above all, he shall under no circumstances kill any animal, and only 
under certain settings enjoy vegetable foods. He has to wear a veil over his mouth in order not to inhale even a small living being; for the same reason he has to filter drinking water and shall not take a bath. (Jahr 2013, 25)

While Jahr seems to consider this position too extreme, he nevertheless aims to transcend the widespread ethical approach driven solely by human interest, in favor of all life.

The second known use of the term bioethics came from the American biochemist and oncologist Van Rensselaer Potter (1911-2001), who was, for a considerable period, credited with coining the term in his 1970 article "Bioethics, the Science of Survival"12 and with founding the field of bioethics. In the text, Potter described bioethics as a new form of interdisciplinary ethics that would integrate biological knowledge and human values, aimed at supporting the survival of the whole ecosystem (Potter 1970, 127-28). He found inspiration for his ideas in the humanities and social sciences, such as the work of the cultural anthropologist Margaret Mead, the philosopher and Jesuit priest Pierre Teilhard de Chardin, and the pragmatists, as well as in the work of the pioneers in environmental ethics, such as Aldo Leopold. ${ }^{13}$ In his later publications, Potter expressed disappointment about the overemphasis that modern bioethicists placed on short-term issues, individual needs, and medical concerns, and he reiterated the need for a wider perspective that he designated as "global bioethics", a discipline that would address and correlate medical, environmental, and social issues as well as adopt a long-term approach (Ten Have 2012, 75-77). ${ }^{14}$ He later included even religious ethics under the umbrella term bioethics (79).

These early visions of bioethics express distinct metaphysical sensibilities inclusive of various life-forms, a future of collective thriving, and the assertion that personal experiences and values are an important part of ethical debate and social development. With a wide-ranging notion of who counts as a moral subject that in several ways resembles Jain ethics, they provide an additional precedent for a Jain engagement with modern bioethics.

As we have highlighted, religious ethics played a formative role in the development of modern bioethics. This means that since its inception as a discipline, bioethics has been shaped by both secular and religious principles. Religious sources were influential even in the case of the more narrow understanding of bioethics as medical bioethics that eventually became predominant. Protestant ethicist Paul Ramsey, Catholic moral theologian Richard A. McCormick, and Jewish theologian Immanuel Jakobovits were but a few of the visible figures who applied their respective traditions' insights on life, death, suffering, and justice to moral issues in medicine. Religious ethicists were key members of early governmental policy committees that issued federal reports and guidelines for human subjects research, forgoing life-sustaining treatment, healthcare access, and the definition of death. Religious authors wrote academic literature ${ }^{15}$ and helped 
initiate organizations that would later become the Kennedy Institute of Ethics at Georgetown University ${ }^{16}$ and the Hastings Center in New York. ${ }^{17}$

Non-Western traditions began to engage the field of Western bioethics in the 1990s. The Dalai Lama was a key figure in opening dialogue between Buddhist philosophy of mind and Western scientists in a series of publicized conversations beginning in 1989. Many books exist today on Buddhist social or ecological ethics, but only a few address bioethics, such as Damien Keown's Buddhism and Bioethics (1995) or Peter Harvey's An Introduction to Buddhist Ethics: Foundations, Values and Issues (2000). Likewise, Hindu bioethics has modest representation, with only a few notable titles: Hindu Ethics: Purity, Abortion, and Euthanasia (1989), edited by Harold Coward, Julius Lipner, and Katherine Young; Dilemmas of Life and Death: Hindu Ethics in North American Context (1995) and Hindu Bioethics for the Twenty-first Century (2003) by S. Cromwell Crawford; and Magical Progeny, Modern Technology: A Hindu Bioethics of Assisted Reproductive Technology (2006) by Swasti Bhattacharyya.

While contemporary Jains encounter the same bioethical issues as everyone else, usually as healthcare users and sometimes as providers, there are no books specifically exploring Jainism in relation to Western bioethics. As noted above, this leaves a gap in the fields of bioethics as well as Jain studies. Several writings exist on Jain ethics generally (Bhargava 1968; Jain 1934; Sethia 2004; Sogani 1967; Williams 1963) as well as on Jain ecology (Chapple 2002; Rankin 2018; Rankin 2019) and, to a lesser extent, Jain business ethics (Shah and Rankin 2017). Bioethics, however, is treated minimally in only a few academic articles, book chapters, and online reflections by contemporary lay Jains or Jain studies scholars (these sources are discussed below).

\section{METHODOLOGY}

As authors, our methodology reflects the approach that would have served us well as younger scholars who came to Jain studies by a circuitous route, often seeking to understand Jain philosophy alongside its textual and historical complexity.

In part 1, we explore foundational principles related to bioethics drawn from in-depth analyses of a wide range of Jain primary sources in Sanskrit and Prakrit. We offer a comprehensive examination of the Jain understanding of birth, life, and death, based on the complex and rarely addressed karmic relationship between material bodies and living, immaterial selves. Further, we offer a distinctive investigation of the development of central Jain ethical principles, including nonviolence, that, in contemporary representations, are too often depicted one-dimensionally, divorced from their wider soteriological framework and historical contexts. Lastly, we trace the Jain attitudes to medicine and medical treatment from the early canon up to the medieval period. 
In part 2, we provide basic overviews of modern bioethical issues and explore Jain principles of application for these dilemmas. Drawing upon several years of teaching courses in multicultural bioethics at the graduate and undergraduate levels, we define key bioethical terms (e.g., autonomy, beneficence, nonmaleficence) and identify key legal precedents, relevant philosophical commitments of other religious communities, and (to a lesser extent) Western normative ethical theories that feature in bioethics debates (e.g., deontology and utilitarianism). Where debates are especially polarized on controversial topics such as abortion or animal research, we map a continuum of ethical positions in order to contextualize contemporary Jain views.

Our research in part 2 is cross-cultural and interdisciplinary, analyzing primary sources in relation to specific bioethical issues as well as scarce contemporary sources on Jainism and bioethics from modern lay Jains, mendicants, and Jain studies scholars. In this portion of the book we also include analyses from two Jain medieval medical treatises-the Kalyāna-kāraka and Taṇụlavaicārika-heretofore largely untranslated into English. Further, we investigate how Jain teachings inform the attitudes and practical decisions of contemporary Jain medical professionals, utilizing data from an original international survey we conducted with Jain medical professionals in India, as well as in diaspora communities of North America, Europe, and Africa. The details and demographics of this survey are introduced in chapter 5. This is the first time, to our knowledge, that such a systematic survey on bioethical attitudes and practices has been attempted among Jain medical practitioners. (Readers interested primarily in the Jain principles of application for bioethical issues can move straight to part 2 of the book.)

Our aim is to provide a comprehensive resource for future scholarship that does not simplify Jain philosophy or ethics for the sake of a surface comparison with modern bioethics or a formulation of a fixed code of conduct for bioethical issues, and the arguments we advance throughout the book are primarily descriptive and analytic. While our work is not prescriptive and aims to highlight the complexity of the approaches within the Jain tradition, we do synthesize and summarize key insights of our description and analysis. In part 1, we conclude each chapter by identifying foundational principles related to bioethics that reflect that chapter's multivalent content. Likewise, in part 2, we conclude each chapter by identifying provisional principles of application that emerge from the interface between traditional textual sources and diverse contemporary Jain views related to modern bioethical dilemmas.

\section{CONSIDERING CONTEMPORARY JAIN VIEWS ON BIOETHICS}

There are very few contemporary sources exploring Jainism and bioethics. Because bioethics is a modern phenomenon, it is outside the purview of traditional textual 
sources. It is also largely outside the realm of Jain mendicants. While some mendicants do offer opinions on social debates and provide guidance to lay Jains, few such sources are widely available. That said, where we have found any relevant mendicant views, we have included them. As a result, the contemporary Jain views presented in part 2 come primarily from lay Jains or Jain studies scholars. Jain studies scholar Christopher Chapple, for instance, has written articles on bioethical themes such as death, synthetic life, and animal research (2010, 2013, 2016a). We also draw upon several other contemporary scholars who have written generally on Jain attitudes toward death and human-animal relations.

Additionally, some literature on bioethics exists from Jain-sponsored conferences or events. These include three international conferences addressing the theme of Jainism and bioethics (in 2012, 2016, and 2017) ${ }^{18}$ and an annual conference hosted by the Gyan Sagar Science Foundation exploring Jainism and science. ${ }^{19}$ Other helpful sources include Jain-created guidelines for hospital staff in the United States and United Kingdom who encounter Jain patients, ${ }^{20}$ reports about a successful political campaign among global Jains to reverse the Indian Supreme Court's decision banning the Jain end-of-life fast known as sallekhanā or samthära ("SC Stays" 2015), and a nascent selection of Jain-created responses to bioethical issues - often found on online forums - that we utilize throughout part 2. Because of the dearth of contemporary resources, we also designed the aforementioned survey for Jain medical professionals.

\section{CHAPTER SUMMARIES}

Part 1 analyzes doctrinal foundations for bioethics in Jainism and includes four chapters. Following this introduction, chapter 2 examines the fundamental assertions of what "exists" in the Jain understanding of reality. We particularly focus on the relationship between life and nonlife that comprises embodied living beings. We lay out the taxonomy of life-forms by way of explaining the distinctions, similarities, continuities, and entanglements between humans, animals, plants, and the unique Jain description of earth-bodied, water-bodied, fire-bodied, and air-bodied beings. We explore how Jains understand (re)birth, life, aging, and death in a given bodily form in relation to multiple varieties of material karma, a technical topic rarely addressed substantively in Jain studies scholarship, especially scholarship for Western audiences less familiar with karmic frameworks. In this context, we delineate, among other things, the Jain conceptions of pain, sentiency, vitalities, instincts, and the violability of life.

Chapter 3 investigates the complex foundations and the development of the Jain notion of right conduct, particularly in relation to nonviolence. We identify underexplored concepts that form the ethical guidelines of the canonical and postcanonical textual sources, such as nonpossession, passions, intention, and "careful" action. We move beyond the general account of the five Jain vows, 
locating the vows as one part of the broader soteriological context described in the fourteen stages of decreased karmic bondage and less harmful action, which present an essential theoretical framework for understanding Jain practice among mendicants and laity.

Chapter 4 explores the Jain approaches to illness and medicine. Given that Jainism originated as an ascetic tradition in which mendicants aimed to transcend the body, the central question of this chapter is whether illness is an occurrence that should be transcended through endurance or whether it can/should be treated. Is medical treatment a transgression of mendicant religious commitments or does a healthy body have a function in such a rigorous ascetic context? The chapter draws from diverse primary sources to identify the meaning of physical and mental illness, Jain attitudes toward the medical treatment of mendicants, and the regulations and exceptions regarding who can receive treatment, who can provide it, and what kind of medications they can use.

In part 2, consisting of three chapters, we identify provisional principles of application deduced from multiple sources expressing Jain views of birth, life, and death.

Chapter 5 introduces our 2017-18 survey methodology and Jain respondents' basic demographics. Following this, we look at the Jain understanding of conception, embryology, fetal life, and maternal connection against the wider backdrop of traditional Indian medicine, including two extant medieval Jain medical treatises. We then examine several bioethical issues related to taking/preventing nascent life (abortion, population control, contraception), facilitating nascent life (IVF, cloning, stem cell research), and altering nascent life (sex selection and genomic editing). We outline current Western bioethical terms, precedents, and debates, followed by various Jain perspectives on these issues. We conclude by identifying provisional Jain principles of reproductive ethics that emerge from the analysis.

Chapter 6 first explores the Jain views of surgery, antibiotics, and vaccinations, highlighting the unique Jain concern for living beings beyond the human community. This is followed by a descriptive overview of clinical bioethical issues related to the physician-patient relationship, research trials, and access to care, including Jain responses to these issues. We pay special attention to how autonomy and truth inform Jain views of clinical practice and research obligations to individual patients and advancing medical knowledge. We outline various ways that contemporary Jain medical professionals maintain their Jain identity alongside competing values of science and society, and conclude with a focused examination of Jain views on using animals for biomedical studies. As before, we close out the chapter by summarizing tentative principles for patient approaches to bioethics and clinical medical practice.

Chapter 7 explores the critical transition of death as an essential ethical moment in the Jain account of rebirth or liberation. Death's certainty figures prominently in Jain texts, which offer detailed descriptions of various kinds of death, alongside 
guidelines for achieving the best death possible. In this chapter we explore ongoing bioethical debates over defining death in modern medicine, its relation to organ donation, and key legal decisions related to refusing life-sustaining treatment and other advance directives. We introduce the Jain practice of voluntary death, exploring its compatibility with and/or distinction from various end-oflife options with varying legal standings globally, including suicide, euthanasia, physician aid-in-dying, terminal sedation, and the voluntary refusal of food and fluids. To close, we identify Jain values that inform a principled approach to death.

The book ends with an epilogue in which we revisit key themes, aims, and methods, highlighting the inherent multiplicity of "Jain" views and identifying possible future areas of research we hope this work might contribute to.

\section{JAINISM AND BIOETHICS: PERSPECTIVES \\ OF A "CUMULATIVE TRADITION"}

We do not advance a single Jain view of bioethics in this book. On the contrary, we have tried to account for the complexity of Jainism as an evolving philosophical system, ethical path, and living religious tradition. Jain studies scholar John Cort has previously argued that Jainism should not be viewed as a set of fixed doctrines across time, but rather as "the sum total of the practices and beliefs of all the people who called themselves Jain throughout the centuries," akin to what Wilfred Cantwell Smith has termed "cumulative tradition" (Wiley 2002, 65).

In line with this, any Jain view of bioethics must contend with fluid foundational principles and varied, open-ended modes of application. As noted above, we have tried to account for a diverse community of Jains from antiquity to the present and in particular historical moments and geographic locales: mendicant and lay Jains, those living in India and those living abroad, distinct diaspora generations, those with diverse sectarian commitments, and those who are professionally employed in medical fields and those who are not, among many other distinctions.

Taking in these multiple views, however, does not mean that we can say nothing overall about Jainism and bioethics. The foundational principles and principles of application we have identified capture distinctive themes, philosophical doctrines, historical and contemporary concerns, and ethical orientations that are uniquely Jain. We hope this work will provide a framework for further scholarship and clinical discourses in many ethical arenas through which to bring Jainism and Jains into critical conversation. 